\title{
DIFFERENT AGE POPULATIONS OF ECLOGITIC DIAMONDS IN THE VENETIA KIMBERLITE: EVIDENCE FROM AR-AR DATING OF SYNGENETIC CLINOPYROXENE INCLUSIONS
}

\author{
Ray Burgess ${ }^{1}$, Gail Kiviets ${ }^{2}$ and Jeff Harris ${ }^{3}$ \\ ${ }^{l}$ Department of Earth Sciences, University of Manchester, Manchester, UK; ${ }^{2}$ DeBeers Geoscience Centre, Southdale, South \\ Africa; ${ }^{3}$ Division of Earth Sciences, University of Glasgow, Glasgow, UK
}

\section{INTRODUCTION}

The Ar-Ar method was the first radiometric dating method to be applied to individual diamonds (Burgess et al., 1989; Phillips et al., 1989) but so far is only applicable to clinopyroxene inclusions in eclogitic diamonds which contain enough potassium. In the past there have been problems in making geological sense of the data obtained. Apparent ages of cleaved diamonds, which exposes the inclusion, range upwards from the eruption age. We have suggested that this is due to diffusion (at mantle temperatures) of ${ }^{40} \mathrm{Ar}$ to the interface between the inclusion and diamond and partial loss of argon when the diamond is cleaved Burgess et al., 1992). To overcome this problem it is necessary to analyse the $\mathrm{Ar}$ content of the inclusion without cleaving. A possible problem arises from the fact that the concentration of "ambient" ${ }^{40} \mathrm{Ar}$ in the mantle is equivalent to several 100's of million years of radiogenic ingrowth of ${ }^{40} \mathrm{Ar}$. However, based on known partition coefficients of ${ }^{40} \mathrm{Ar}$ between minerals and melts it is unlikely that much of the ambient argon component is incorporated into the clinopyroxene minerals. On a worst case scenario the age based on total ${ }^{40} \mathrm{Ar} /{ }^{39} \mathrm{Ar}$ is an absolute upper limit to the time at which the clinopyroxene was encased by the diamond. In this study, present Ar-Ar results from five clinopyroxene-bearing eclogitic diamonds from the Venetia mine, South Africa. We have used a new analytical approach to preferentially extract surfaceand volume-related Ar components from the inclusions.

\section{EXPERIMENTAL METHODS}

Each diamond was cut and polished to within approximately $1 \mathrm{~mm}$ of the pyroxene surface. The position of the inclusion was marked by a laser pits (Fig. 1) so that it could be accurately located once nuclear irradiation which makes the host diamond opaque. Following irradiation, an ultra-violet (UV) laser $(266 \mathrm{~nm})$ in was used to drill down to the inclusions. This was done to release any interface $\mathrm{Ar}$ that may be present. The diamond was then transferred to a resistance furnace in which the sample was heated between $600-2150^{\circ} \mathrm{C}$ in six temperature increments to release volume-related ${ }^{40} \mathrm{Ar},{ }^{39} \mathrm{Ar}_{\mathrm{K}}$ and ${ }^{37} \mathrm{Ar} \mathrm{ra}_{\mathrm{Ca}}$ from the inclusion. The age calculated from the total ${ }^{40} \mathrm{Ar} /{ }^{39} \mathrm{Ar}$ ratio should give the time at which the inclusion was trapped in the diamond.

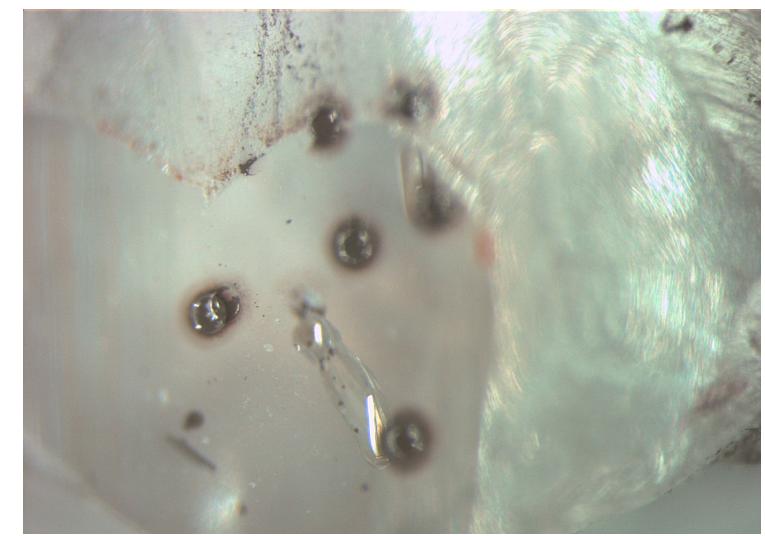

Figure 1: Photograph of Venetia diamond showing clinopyroxene inclusion. The diamond has been cut and polished to within approx. $1 \mathrm{~mm}$ of the inclusion. Dark circles are UV laser ablation pits to help locate the inclusion following irradiation. Field of view is approx. $3 \mathrm{~mm}$.

\section{RESULTS AND DISCUSSION}

One of the clinopyroxene-bearing diamonds released a very small amount of argon and is not considered further. UV laser drilling of the remaining four samples released a maximum of only $3 \%$ of the total ${ }^{40} \mathrm{Ar}$, and yielded apparent ages of between $500 \mathrm{Ma}$ and $2500 \mathrm{Ma}$. The Ar released during stepped heating can be broadly divided into a low temperature release between 1200$1800^{\circ} \mathrm{C}$, associated with the major release of ${ }^{37} \mathrm{Ar}_{\mathrm{Ca}}$ and therefore attributed to the melting of pyroxene, and a high temperature release at $2150^{\circ} \mathrm{C}$ from diamond graphitisation. Two of the samples gave ages of $514 \pm$ $25 \mathrm{Ma}$ (Fig. 2) and $535 \pm 26 \mathrm{Ma}$ (1 sigma error) from pyroxene, which are indistinguishable from the published age of the Venetia kimberlite of $519 \pm 6 \mathrm{Ma}$ (Phillips et al., 1999). It is therefore concluded that 
these two diamonds must have formed within a period of about $50 \mathrm{Ma}$ before kimberlite emplacement. Low temperature releases from the two remaining diamonds gave much higher apparent ages of $2237 \pm 20 \mathrm{Ma}$ and $2508 \pm 140 \mathrm{Ma}$. Releases at $2150^{\circ} \mathrm{C}$ from all the diamonds gave much higher apparent ages (some $>4500 \mathrm{Ma}$ ) attributed to the presence of excess ${ }^{40} \mathrm{Ar}$ in the host diamond.

The release of negligible ${ }^{40} \mathrm{Ar}$ during laser drilling from these two diamonds implies that ${ }^{40} \mathrm{Ar}$ is not stored at the inclusion-diamond interface. Previously, Kelley et al. (2000) have obtained geologically meaningful pre-eruption ages from mantle xenoliths. They have argued that it is possible to retain radiogenic ${ }^{40} \mathrm{Ar}$ in minerals under mantle conditions. In diamonds, it is likely that the void space and cracks associated with the inclusions that are observed under surface conditions, may not have been present as storage sites for ${ }^{40} \mathrm{Ar}$ during mantle residence. Based on the limited number of samples we have analysed there appear to be at least two populations of Venetian eclogitic diamonds. If Kelley et al., model applies then it could also be argued that the 2300 ages may be unrelated to diamond genesis, but simply represent the time of crystallisation of the pyroxene grains prior to their encapsulation in diamond.

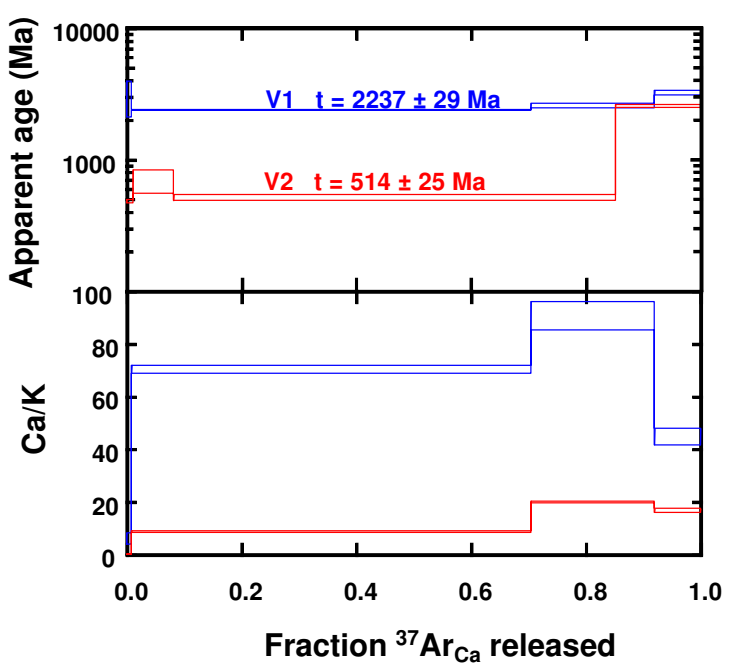

Figure 2: Apparent age and $\mathrm{K} / \mathrm{Ca}$ spectra for two clinopyroxene-bearing Venetian diamonds obtained by stepped heating. The fraction of Ca-derived ${ }^{37} \mathrm{Ar}$ is used to emphasise that the most precise ages are obtained during Ar release from Ca-rich pyroxene. High apparent ages coincide with a decrease in $\mathrm{Ca} / \mathrm{K}$ value at high temperature, is considered to be from the host diamond and has no geological significance.

\section{REFERENCES}

Burgess, R., Turner, G., Laurenzi, M., Harris, J.W., 1989. ${ }^{40} \mathrm{Ar}-{ }^{39} \mathrm{Ar}$ laser probe dating of individual clinopyroxene inclusions in Premier eclogitic diamonds. Earth Planet. Sci. Lett. 94, 22-28.

Burgess, R., Turner, G., Harris J.W., 1992. ${ }^{40} \mathrm{Ar}-{ }^{39} \mathrm{Ar}$ laser probe studies of clinopyroxene inclusions in eclogitic diamonds. Geochim. Cosmochim. Acta 56, 389-402.

Kelley, S.P. and J-A. Wartho, J.A, 2000. Rapid kimberlite ascent and the significance of Ar-Ar ages in xenolith phlogopites. Science, 289, 609-611.

Phillips, D., Onstott, T.C., Harris J.W., 1989. 40Ar/39Ar laser-probe dating of diamond inclusions from the Premier kimberlite. Nature 340, 460-462.

Phillips, D., Kiviets, G.B., Barton, E.S., Smith, C.B., Viljoen, K.S., Fourie, L.F., 1999. ${ }^{40} \mathrm{Ar} /{ }^{39} \mathrm{Ar}$ dating of kimberlites and related rocks: problems and solutions. Proc. 7th Internat. Kimb. Conf. 677-688.

Contact: R Burgess, Department of Earth Sciences, University of Manchester, Oxford Rd., Manchester, M13 9PL, UK, Email: Ray.Burgess@man.ac.uk 